\title{
Friction and wear behavior of different seal materials under water-lubricated conditions
}

\author{
Weigang ZHAO ${ }^{1}$, Guoyuan ZHANG $^{2, *}$, Guangneng DONG ${ }^{3}$ \\ ${ }^{1}$ School of Astronautics, Northwestern Polytechnical University, Xi'an 710072, China \\ ${ }^{2}$ School of Mechano-Electronic Engineering, Xidian University, Xi'an 710071, China \\ ${ }^{3}$ Key Laboratory of Modern Design and Rotor-bearing System of Ministry of Education, Xi'an Jiaotong University, Xi'an \\ 710049, China
}

Received: 25 December 2018 / Revised: 14 June 2019 / Accepted: 10 January 2020

(C) The author(s) 2020 .

\begin{abstract}
The shaft mechanical face seal in a high-speed turbopump of a liquid rocket engine often operates under extremely harsh conditions. For example, a low-temperature and low-viscosity fluid (such as liquid oxygen or liquid hydrogen) is used as a lubricant. The performance of the seal rings, especially the friction and wear behavior, directly determines whether the seal functions normal. In this study, the friction and wear behavior of several ring materials are tested using a pin-on-disk tribo-tester, and the wear morphology of the ring is investigated. The friction coefficients (COFs) and mass-wear rates under dry-friction and water-lubricated conditions, which are used to simulate low-viscosity conditions, are obtained. The results show that at a pressure-velocity (PV) value of $2.4 \mathrm{MPa} \cdot(\mathrm{m} / \mathrm{s})$, the COF between the copper graphite (stator) and copper-chrome alloy disk (rotor) is low (with a value of 0.18) under the dry-friction conditions, and the 5-min wear mass of the copper graphite is approximately $2 \mathrm{mg}$. Under the water-lubricated conditions, compared with other materials (such as copper-chrome alloy, S07 steel, alumina ceramic coating, and nickel-based calcium fluoride), the S07 steel with a diamond-like carbon film is preferred for use in a high-speed turbopump under extreme conditions. The results of this study can provide theoretical and experimental guidance in the design of mechanical face seals in liquid rocket engines.
\end{abstract}

Keywords: friction; wear; mechanical face seal; water-lubricated; high-speed turbopump

\section{Introduction}

Because the high-speed turbopump in a liquid rocket engine operates under extreme operating conditions, the shaft mechanical face seal in the turbopump is often made of a metal rotor and a graphite ring as the stator, which includes copper graphite rings $[1,2]$. However, with the development of the nextgeneration high-speed turbopump under cryogenic liquid environments, the materials used for seal rings (including that of the rotor and stator) must adapt to harsh working conditions such as those in a low-temperature and low-viscosity fluid. Hence, the research on new mechanical-seal materials for extreme conditions has become increasingly important.

In the past 10 years, some researchers have conducted studies on seal-material performance (especially the friction coefficients (COFs) and wear behavior) under different extreme conditions. For example, Yi et al. [3] investigated the friction and wear behavior of several types of middle-temperature abradable seal coatings used in aircraft turbine engines. The coefficient

* Corresponding author: Guoyuan ZHANG, E-mail: gyzhang@xidian.edu.cn 
of dynamic friction and wear of dynamic sealing elements in water pumps of automotive combustion engines were experimentally determined by Deprez et al. [4]. Hirani and Goikar [5] investigated the friction and wear characteristics of an antimony-impregnated carbon-graphite material used in a steam rotary joint, and the wear loss, friction torque, and surface temperature of the sealing surfaces were measured under dry, water, and steam lubrication conditions. Wang et al. [6] developed a C-coating deposited onto a $9 \mathrm{Cr} 18$ rotor of the face seal in liquid rocket engine turbopumps, and the tribological performance of each specimen was tested under three sealedfluid conditions (air, water, and liquid nitrogen). Young et al. [7] investigated the macro/microlaser machined characteristics of mechanical face seals, and friction-testing experiments using water for the seal were conducted. Zhao et al. [8] studied the frictional performance of silicon carbide underwater and lubrication-absent conditions by using a Falex1506 tribo-tester and different working parameters. Frölich et al. [9] developed a macroscopic simulation model for the radial shaft seals and the results of simulations using their model showed that the material of the seal ring is intensely influenced by both the temperature and the contact pressure. Cui et al. [10] developed new self-lubricating bronze matrix composites for seals and explored the tribological mechanisms in antiwear hydraulic oil using a ballon-disk tribo-tester. In summary, previous studies have indicated that the study on the suitability of materials for the seal's pairs and the improvement of materials' surface properties can significantly improve the friction and wear performance of the seal under the extreme conditions, and these results also provided the important ideas and methods for selecting material, treating surface, improving the tribological performance and even monitoring tribological behavior of the mechanical seal [11]. The mechanical seal in a liquid rocket engine is designed as a noncontact seal, however, during the start-up stage, the seal works in a contact status [12]. The seal is immersed in low-viscosity liquid nitrogen. Thus, learning the performance of the contact seal and its tribological behavior under dry and low-viscosity-fluid lubrication conditions is very important. To simulate a low-viscosity condition, water is often used in the experiment.

To improve the mechanical-seal contact performance, metal-ring (rotor) coating (or film) treatment has become a very important research focus. Significant concern has been reported regarding friction and wear of the coatings in water and air, and mechanical seals are considered owing to their potential applications [6, 13-17]. The typical working conditions of the mechanical seal in a liquid rocket engine are low temperature, low viscosity, and high-PV values. The present study mainly focuses on obtaining the tribological performance of different seal materials under low-viscosity-fluid lubrication and high-PV conditions. In consideration of the safety in the experimental process and actual test conditions, the influence of low temperature is not considered. Studies on the performance of this type of mechanical seals under such harsh conditions require gradual transition and development from the poor lubrication of lowviscosity fluid tests (such as in dry friction and waterlubricated conditions) to low-temperature liquidnitrogen simulation, and finally to actual liquidoxygen or liquid-hydrogen experiments. The process has also been the general development idea of related research progress. For example, the research on mechanical seal for a liquid rocket engine, dry friction, water-lubricated conditions, and liquid-nitrogenlubricated conditions were gradually proposed, and the corresponding tests were carried out, as presented in Refs. [2, 12, 16, 18-20].

In the present study, five materials for mechanical face-seal pairs (S07 steel, alumina ceramic coating, diamond-like carbon (DLC) film, copper-chromium alloy, and nickel-based calcium fluoride) are proposed, and their friction and wear behavior are investigated under dry-friction and water-lubricated conditions. The results provide both theoretical and experimental guidance for the design of mechanical face seals in a liquid rocket engine.

\section{Experimental}

\subsection{Test equipment}

The equipment for the pin-on-disk test is a UMT-2 
testing machine equipped with a rotating module. The rotation-speed range is $50-2,500 \mathrm{r} / \mathrm{min}$, and the load range is $5-150 \mathrm{~N}$. In the experimental process, the pin sample is a copper graphite pin (stator ring seal material), which is clamped by a fixture connected to a multidirectional sensor. The disk sample, which is made of the same material as the rotor, is fixed on the pedestal and driven by a stepping motor. During the test, the pin sample is kept static and the disk is rotated at the designed speed. In this manner, the actual seal contact-friction status can be simulated.

\subsection{Pin and disk sample for the test}

\subsubsection{Pin sample}

The material of the cone pin is copper-based graphite, and the sample is fabricated by cutting an actual blank of the seal stator. The large-end-diameter of the cone pin is $6 \mathrm{~mm}$, and the thin-end diameter is $2.5 \mathrm{~mm}$. The density of the copper-based graphite material is $6.61 \mathrm{~g} / \mathrm{cm}^{3}$, and its hardness is $50 \mathrm{HB}$. The pin sample is shown in Fig. 1.

\subsubsection{Disk samples}

In this study, five materials for the seal pairs are used as follows: S07 steel disk [0Cr16Ni6 (Table 1 lists the ingredients in $\mathrm{wt} \%)]$, alumina ceramic coating disk, S07 steel disk with a DLC film, copper-chromium alloy disk (high-thermal-conductivity material), and nickel-based calcium fluoride disk (composite selflubricating material).

All the disk samples are shown in Fig. 2. The surface roughness values of the disks are listed in Table 2.

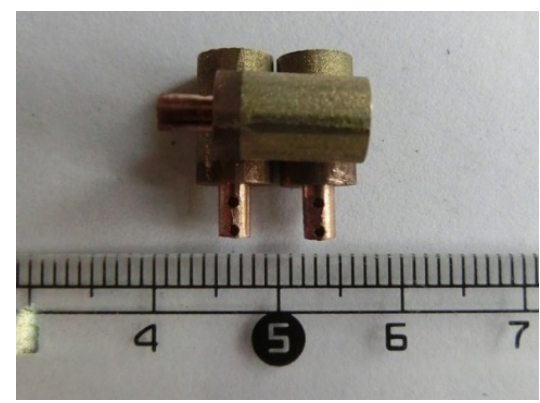

Fig. 1 Pin for test.

Table 1 Composition of S07 steel.

\begin{tabular}{cc}
\hline Composition & $(\mathrm{wt} \%)$ \\
\hline $\mathrm{C}$ & 0.07 \\
$\mathrm{Mn}$ & 0.50 \\
$\mathrm{Cr}$ & 16 \\
$\mathrm{Ni}$ & 6 \\
$\mathrm{Ti}$ & $\leqslant 0.05$ \\
\hline
\end{tabular}
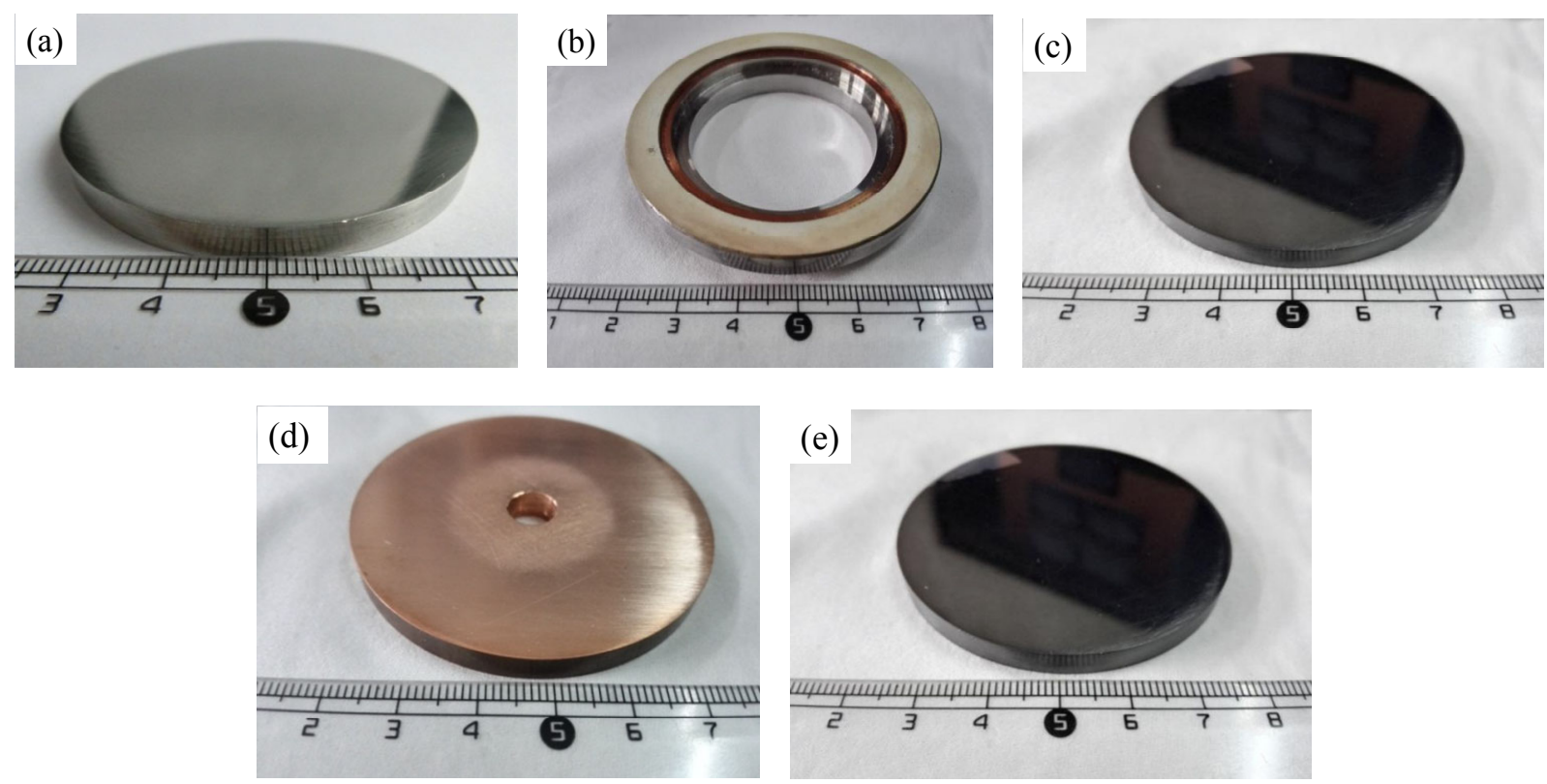

Fig. 2 Disk samples: (a) S07 steel disk (sample A), (b) alumina ceramic coating disk (sample B), (c) S07 steel disk with DLC film (sample C), (d) copper-chromium alloy disk (sample D), and (e) nickel-based calcium fluoride disk (sample E). 
Table 2 Surface roughness of the disks.

\begin{tabular}{ccc}
\hline Disk & $\begin{array}{c}\text { Sample } \\
\text { number }\end{array}$ & $\begin{array}{c}\text { Roughness } \\
(\mu \mathrm{m})\end{array}$ \\
\hline S07 steel disk & $\mathrm{A}$ & 0.01 \\
Alumina ceramic coating disk & $\mathrm{B}$ & 0.01 \\
$\begin{array}{c}\text { S07 steel disk with DLC film } \\
\text { Copper-chromium alloy disk } \\
\begin{array}{c}\text { Nickel-based calcium } \\
\text { fluoride disk }\end{array}\end{array}$ & $\mathrm{C}$ & 0.01 \\
\hline
\end{tabular}

\subsection{Experimental design}

The shaft mechanical face seal in a high-speed turbopump is a noncontact-type seal, and the principle diagram is shown in Fig. 3. The rotor is fixed on the shaft using a tightening bolt. The stator is supported by axisymmetric springs, which are mounted at the end cover. An additional static O-ring is used to prevent the sealed fluid from leaking into the cover. The gap (i.e., the seal-fluid thickness) between the rotor and stator is less than tens of micrometers only. The seal can work in a noncontact status owing to the fluid-dynamic effect that originates from the high rotational speed of the shaft.

\subsubsection{Experimental design under dry-friction condition}

The pairs (pin and disk) are arranged using a pinon-disk contact under dry condition. Velocity $(V)$ in the test is $0.6 \mathrm{~m} / \mathrm{s}$. During the test process, all tests are completed with sufficient sliding time, and the sliding time is longer than the running-in period. In this study, the test time is uniformly set to $5 \mathrm{~min}$ to facilitate an easy comparison of the wear rate of the different samples. During the 5-min experiment process, we observe that the COF of the samples can reach a stable range.

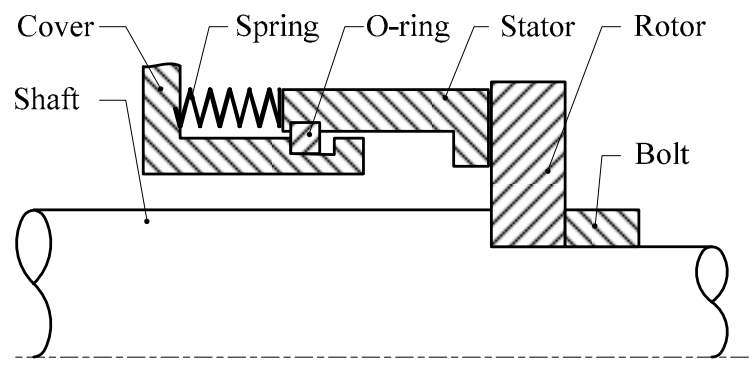

Fig. 3 Diagram of the non-contact mechanical seal.
The PV value is equal to pressure $(P)$ times $V$. The force $(F)$ and PV value in the test are listed in Table 3. The PV values are defined by the actual engineering-design parameters. The PV values under the dry-friction and water-lubricated conditions are different because the actual engineering conditions of the mechanical seal in the liquid rocket engine are considered.

In Refs. [1, 19, 20], it was demonstrated that when the speed is lower than the separated speed (the speed is a critical speed used to determine whether the tribology pairs (rotor and stator) of the mechanical face seal is in contact status), the mechanical face seal in the turbopump that uses a sealed fluid is a seal-type contact seal, and the closing force consists of the spring force and sealing-fluid static pressure. According to the parameters of the seal and spring force $(226 \mathrm{~N})$, the typical pressure value between the pairs (stator and rotor or pin and disk) of the contact seal under the sealing pressure of $1.5 \mathrm{MPa}$ is $2.2 \mathrm{MPa}$. Hence, the range of the PV value under the dry-friction and low-speed (considering the static pressure only) conditions are set from 0.5 to $3.0 \mathrm{MPa} \cdot(\mathrm{m} / \mathrm{s})$.

\subsubsection{Experimental design under water-lubricated conditions}

By adding an appropriate amount of water to the disk surface, a water-lubricated state is simulated. $V$ in the test is $1.2 \mathrm{~m} / \mathrm{s}$. The load and PV values of the test are listed in Table 4 .

Table 3 Experimental design under the dry-friction conditions.

\begin{tabular}{ccc}
\hline $\mathrm{PV}(\mathrm{MPa} \cdot(\mathrm{m} / \mathrm{s}))$ & $P(\mathrm{MPa})$ & $F(\mathrm{~N})$ \\
\hline 0.6 & 1 & 5.02 \\
1.2 & 2 & 10.05 \\
1.8 & 3 & 15.06 \\
2.4 & 4 & 20.08 \\
3.0 & 5 & 25.08 \\
\hline
\end{tabular}

Table 4 Experimental design under the water-lubricated conditions.

\begin{tabular}{ccr}
\hline $\mathrm{PV}(\mathrm{MPa} \cdot(\mathrm{m} / \mathrm{s}))$ & $P(\mathrm{MPa})$ & $F(\mathrm{~N})$ \\
\hline 15 & 12.5 & 62.76 \\
20 & 16.7 & 83.69 \\
25 & 20.8 & 104.58 \\
30 & 25.0 & 125.53 \\
\hline
\end{tabular}


The water-lubricated state is designed to simulate the existence of a water film between the gap in the seal pairs (rotor and stator), and the contacting state may represent a mixed-lubrication condition. In the test process, the supply of water is continuous, and the contact interface of the pairs is soaked in water. As previously mentioned, the mechanical face seal in the turbopump is a noncontact seal type. When the speed is higher than the separated speed, the pressure under the water-lubricated condition is higher than that under the dry-friction condition. The typical PV value between the seal faces (stator and rotor) is approximately $25 \mathrm{MPa} \cdot(\mathrm{m} / \mathrm{s})$ (separated speed of 9,750 rpm [1], and the pressure of fluid, $0.5 \mathrm{MPa})$. Hence, the range of PV values is set from 15 to $30 \mathrm{MPa} \cdot(\mathrm{m} / \mathrm{s})$.

\section{Results and discussion}

\subsection{Results under dry-friction condition}

Figures 4-8 show the results of the COFs and wear rate of the different materials in the friction pairs under dry-friction conditions. The wear rate is defined as the difference between the measured mass of the sample using a precision balance (accuracy level, $0.01 \mathrm{mg}$ ) before and after the test.

Figure 4(a) shows that when the friction pair consists of the copper-based graphite pin and S07 steel disk, the COFs slightly change with the change in the load, and a stable COF is maintained at a low-value range from 0.15 to 0.25 . When the PV

(a)

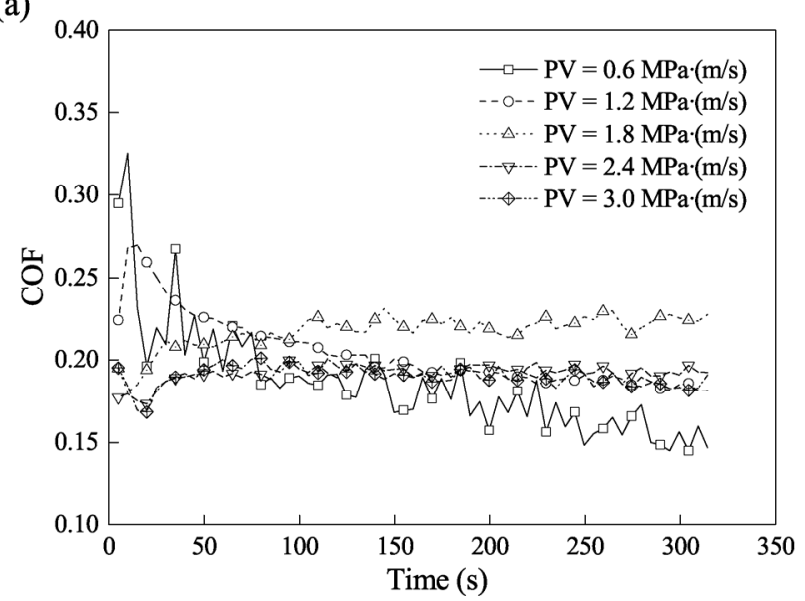

value is lower than $1.8 \mathrm{MPa} \cdot(\mathrm{m} / \mathrm{s})$, the COFs increase with increasing load. When the PV value is higher than $1.8 \mathrm{MPa} \cdot(\mathrm{m} / \mathrm{s})$, the COFs hardly change and remain at approximately 0.2 . At the beginning of the friction test, the COFs show a complex fluctuation state regardless of the load due to the lack of a stable transfer film. After $50 \mathrm{~s}$ from the test start, the COFs become stable. Figure 4(b) shows that the wear rate of the copper-based graphite pin increases with the PV value, and the increasing variation range is from 0.4 to $6.5 \mathrm{mg}$.

Figure 5(a) shows that the COFs of the alumina ceramic coating disk slightly change with increasing load when $\mathrm{PV} \leqslant 1.8 \mathrm{MPa} \cdot(\mathrm{m} / \mathrm{s})$, whereas the COFs remain fairly constant at the load of $\mathrm{PV}>1.8 \mathrm{MPa} \cdot(\mathrm{m} / \mathrm{s})$. Figure 5(b) shows that the wear rate of the copperbased graphite pin increases with the increase in the PV value. The wear rate changes from 1.7 to $7.9 \mathrm{mg}$.

Figure 6(a) shows that the $\mathrm{COF}$ at $\mathrm{PV}=0.6$ $\mathrm{MPa} \cdot(\mathrm{m} / \mathrm{s})$ greatly fluctuates with the test time, and the COF changes from 0.13 to 0.2 . When the $\mathrm{PV}$ value is higher than $0.6 \mathrm{MPa} \cdot(\mathrm{m} / \mathrm{s})$, the COFs decrease from 0.20 to 0.17 with the increase in load. Under high-load conditions, a DLC transfer film can easily form, allowing the COFs to remain constant with the test time. Figure $6(\mathrm{~b})$ shows that with the increase in the PV value, the wear rate of the copper-based graphite pin exhibits a little change. The wear rate slightly increases with the load from 2.6 to $3.2 \mathrm{mg}$.

Figure 7(a) shows that the COFs do not change regularly in a regular manner with the change in

(b)

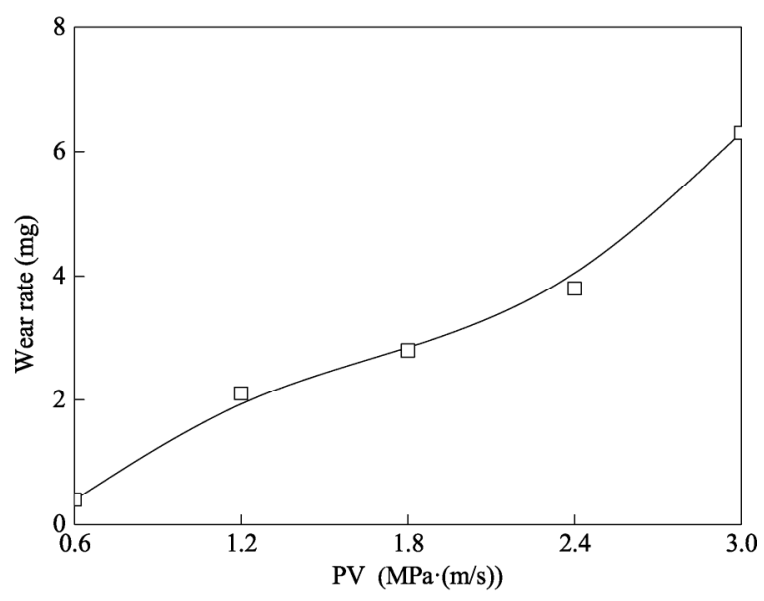

Fig. 4 (a) COFs and (b) wear rate with the S07steel disk under the dry-friction conditions. 
(a)

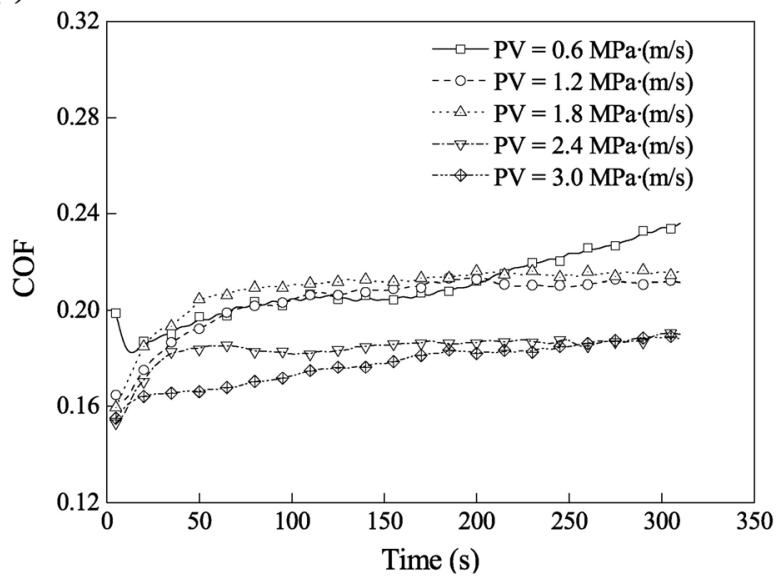

(b)

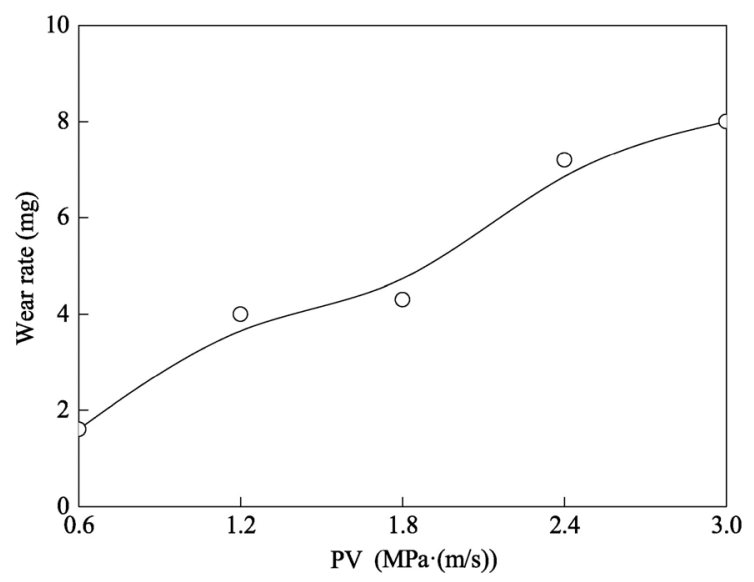

Fig. 5 (a) COFs and (b) wear rate with the alumina ceramic coating disk under the dry-friction conditions.

(a)

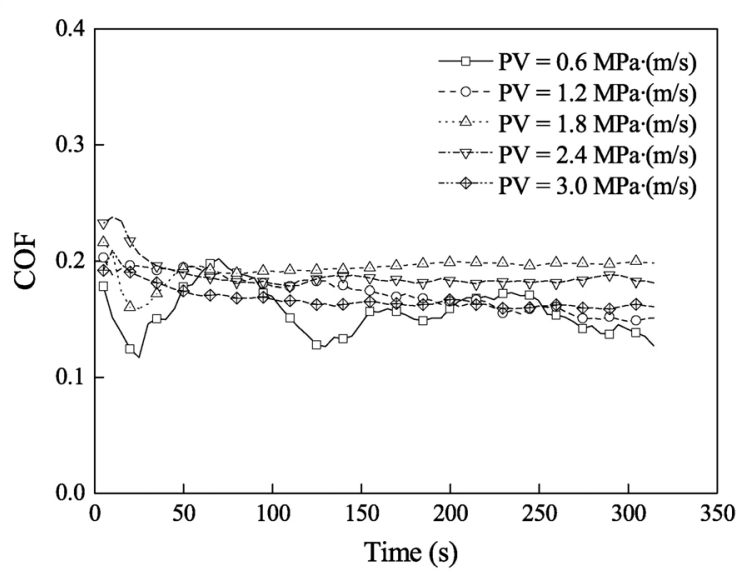

(b)

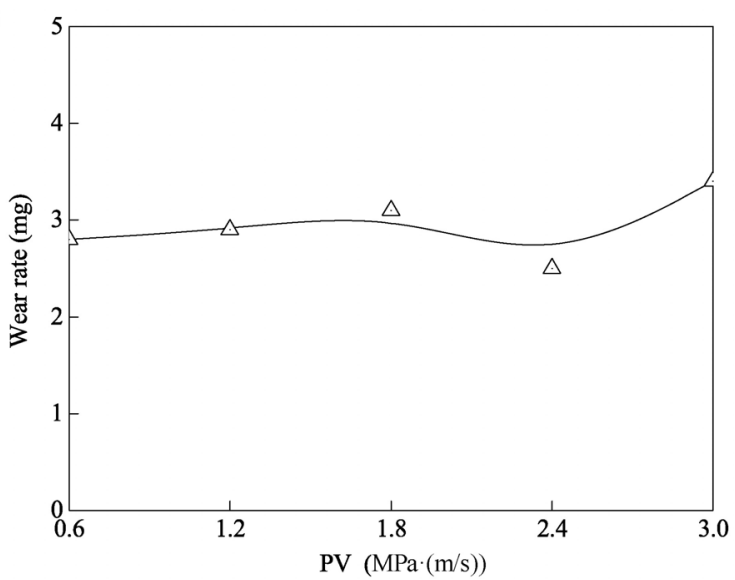

Fig. 6 (a) COFs and (b) wear rate with the S07 steel disk with DLC film under the dry-friction conditions.

the load when the pair of materials consists of copper-based graphite pin and copper-chrome alloy disk. The COFs change from 0.15 to 0.22 . The transfer film on the surface of the disk appears to form easily, and thereby allowing the COFs to exhibit a stable result. Figure 7(b) shows that the wear rate of the copper-based graphite pin is small and increases with the increase in the PV value. Under different PV conditions, the difference in the wear rate is very small. The friction reduction and wear resistance of this copper-chrome alloy disk is good.

Figure 8(a) shows that the COF of the copperbased graphite pin and nickel-based calcium fluoride disk gradually decreases with the increase in the load. The COF is less than 0.2 when PV is more than $0.6 \mathrm{MPa} \cdot(\mathrm{m} / \mathrm{s})$. Figure $8(\mathrm{~b})$ shows that when $\mathrm{PV} \leqslant 1.8 \mathrm{MPa} \cdot(\mathrm{m} / \mathrm{s})$, the wear rate of the copperbased graphite pin increases with the increase in the load. When PV $>1.8 \mathrm{MPa} \cdot(\mathrm{m} / \mathrm{s})$, the wear rate slightly changes with the change in PV.

Figure 9 shows a summary of the average COF and wear-rate results of the different materials under dry-friction conditions. The comparisons of the COFs and wear rate of the different materials are also presented.

When the variation in the COF with time is steady ( $T \geqslant 300 \mathrm{~s})$, the special coefficient is defined as the average $\mathrm{COF}$, which represents the COF when the running-in period is finished and the operation is within a stable range.

Figure 9(a) shows that under the dry-friction condition, the average COFs of all disks decrease with the load, except for sample A and sample C. Thus, the other disks exhibit a good anti-friction effect. Moreover, the COFs of sample E are low and more stable than those of the other disks. 
(a)

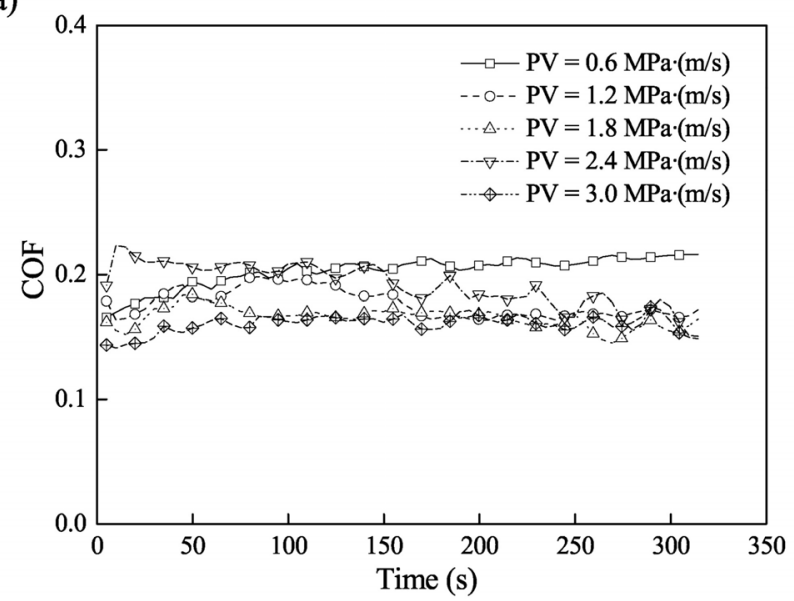

(b)

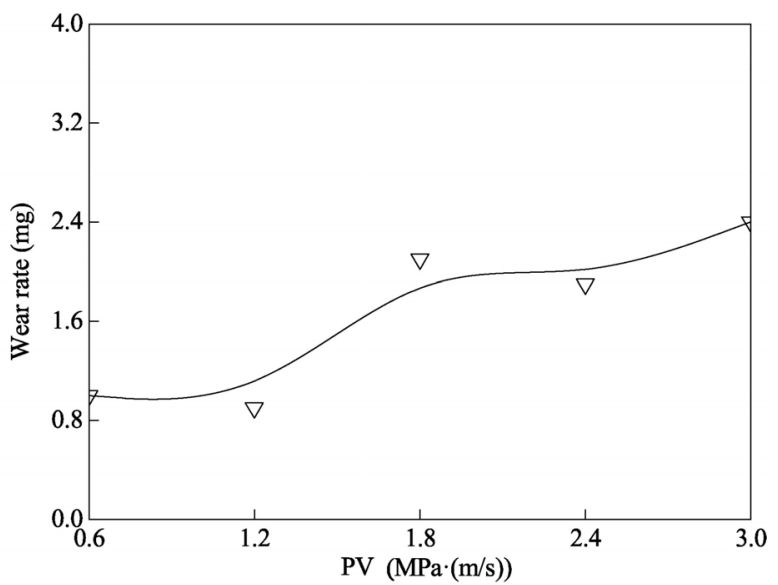

Fig. 7 (a) COFs and (b) wear rate with the copper-chromium alloy disk under the dry-friction conditions.

(a)

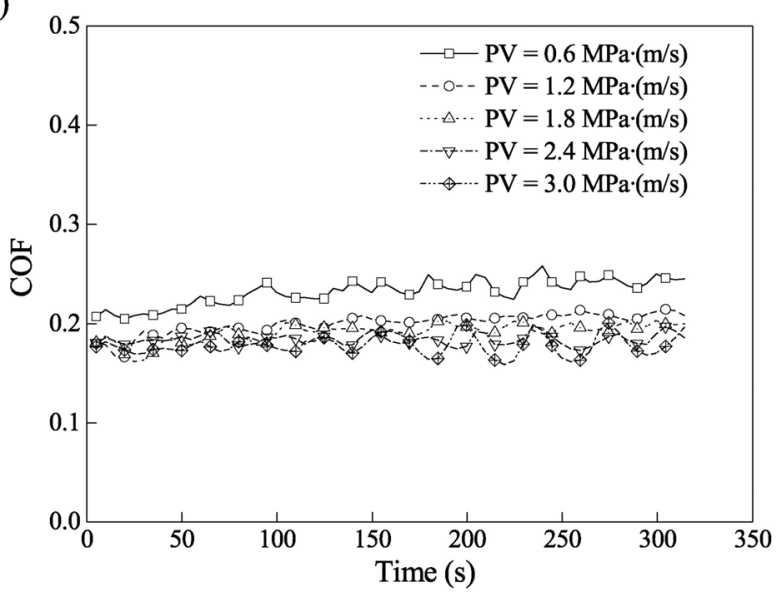

(b)

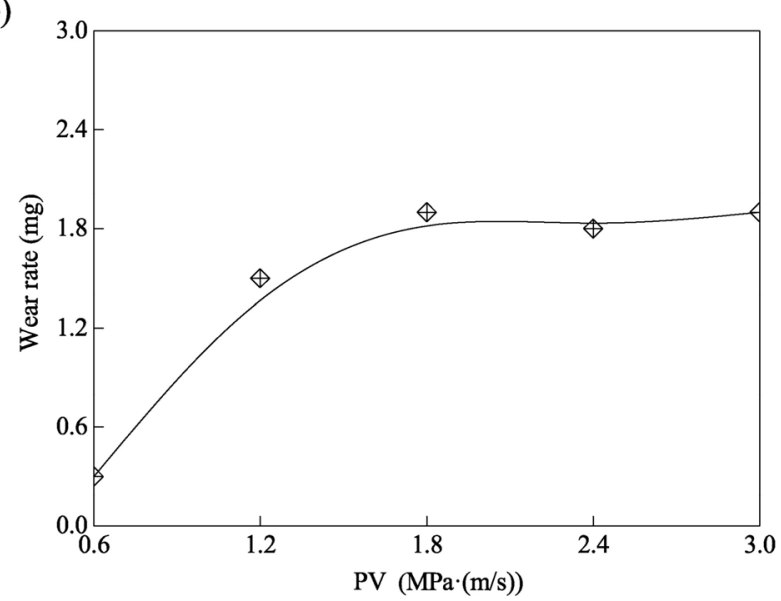

Fig. 8 (a) COFs and (b) wear rate with the nickel-based calcium fluoride disk under the dry-friction conditions.

(a)

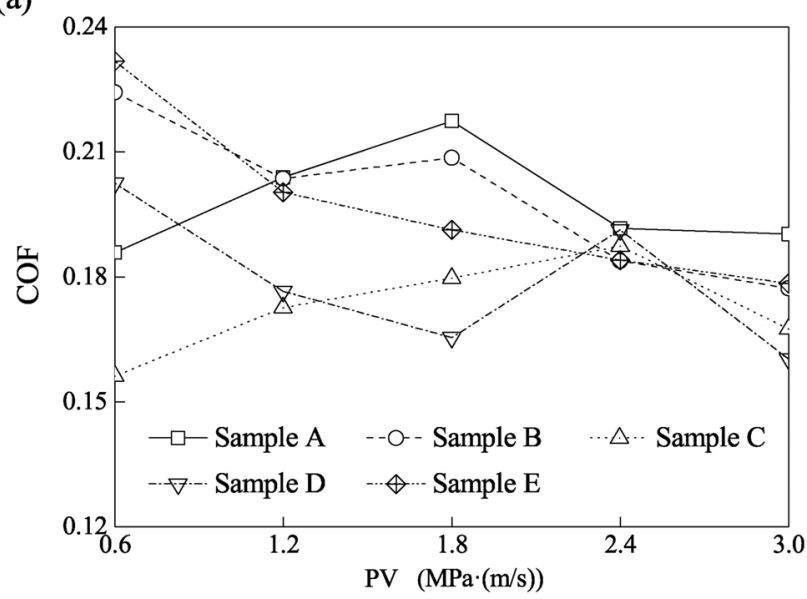

(b)

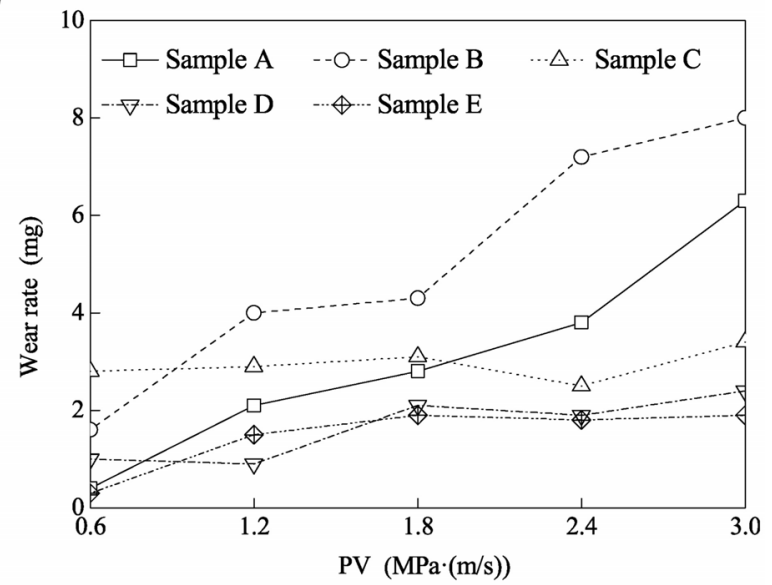

Fig. 9 (a) Average COF and (b) wear rate results with the different materials under the dry-friction conditions. 
Figure 9(b) shows that under the dry-friction condition, the wear rate increases with the increase in the load. The wear rates of sample D and sample $\mathrm{E}$ are the lowest. Moreover, the wear rate of the S07 steel disk with a DLC film maintains low-level stability and exhibits little change as PV value increases.

\subsection{Results under water-lubricated condition}

Figures 10-12 show the results of the COFs and wear rate using different materials as friction pairs under a water-lubricated condition. The tests for sample B and sample E under the water-lubricated condition are not carried out because of the similar serious wear rate under the dry-friction condition (Fig. 5) and poor water compatibility of the coating.

Figure 10(a) shows that under the water-lubricated condition, the COFs of the copper-based graphite pin and S07 steel disk decrease with the increase in

(a)

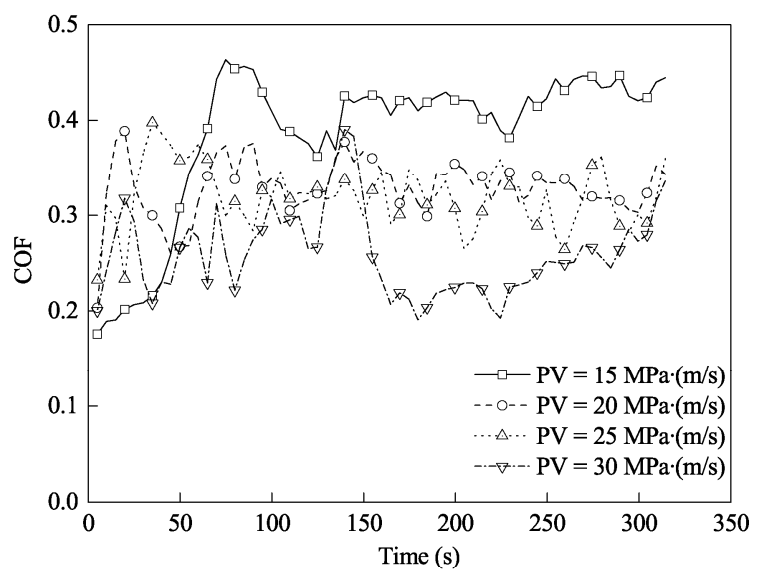

(b)

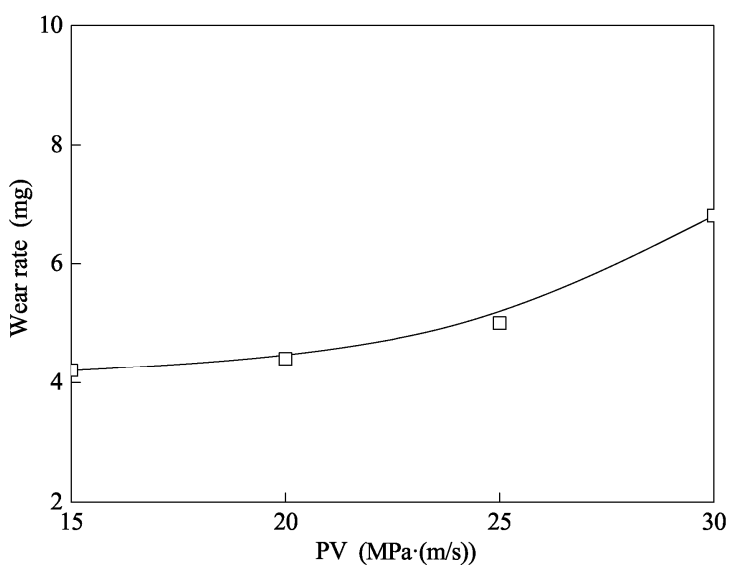

Fig. 10 (a) COFs and (b) wear rate with the S07steel disk under the water-lubricated conditions.

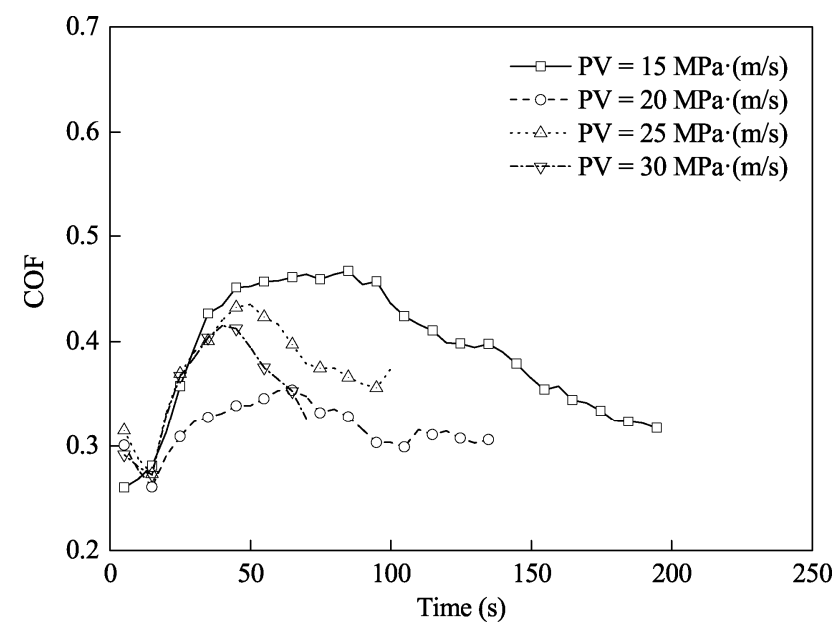

Fig. 11 COFs with the copper-chromium alloy disk under the water-lubricated conditions.

the PV values. The maximum and minimum COFs are 0.45 and 0.18 , respectively. The difference between the maximum and minimum COFs is large. Figure 10(b) shows that the wear rate of the copper-based graphite pins increases with the increase in the PV value. The wear rate varies from 4 to $7 \mathrm{mg}$ with an increase in PV.

When the pair consists of the copper-based graphite pin and copper-chrome alloy disk, the pin wear becomes serious. In a very short time, the pins are worn out. The curves of the COFs in Fig. 11 show that the higher the PV value is, the shorter is the wear time of the pin. The reason for this could be that the hardness of the copper-chrome alloy disk (approximately $75 \mathrm{HRB}$ or more than $120 \mathrm{HB}$ ) is significantly higher than that of graphite (approximately $50 \mathrm{HB})$. Meanwhile, the self-lubricating property of the solid graphite under the water-lubricated condition is weakened. Thus, the pin anti-wear performance is much better under the dry-friction condition.

Figure 12(a) shows that the COF is stable and remains at a low-stability level when the pair consists of the copper-based graphite pin and S07 steel disk with a DLC film. The COFs decrease with increasing PV values. The DLC film demonstrates a good anti-friction performance. Figure 12(b) shows that with the increase in the PV value, the copperbased graphite pin-wear increases.

Figure 13 shows a summary of the average COF and wear-rate results of the different materials under 
the water-lubricated condition. Comparisons of the COFs and wear rate of the different materials are also provided.

Figures 13(a) and (b) show that under high PV values and water-lubricated conditions, the COFs of the steel disk are stable and the wear rate is low. Moreover, the COFs of the DLC film steel disk are stable, but the wear rate shown in Fig. 13(b) is higher than that of the other materials. Thus, through comparison of the friction and wear behavior of these materials, the steel disk with a DLC film is found to be a more suitable seal under the waterlubricated condition.

\subsection{Results of the surface morphology of different materials under water-lubricated condition}

Figures 14-16 show the wear surface topography of the different materials (S07 steel disk, copperchromium alloy disk, and S07 steel disk with a DLC film) under the water-lubricated condition.

(a)

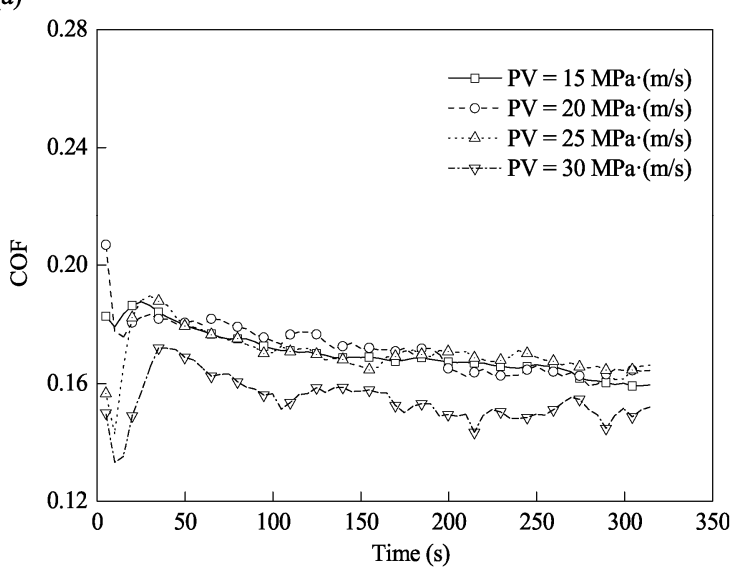

(b)

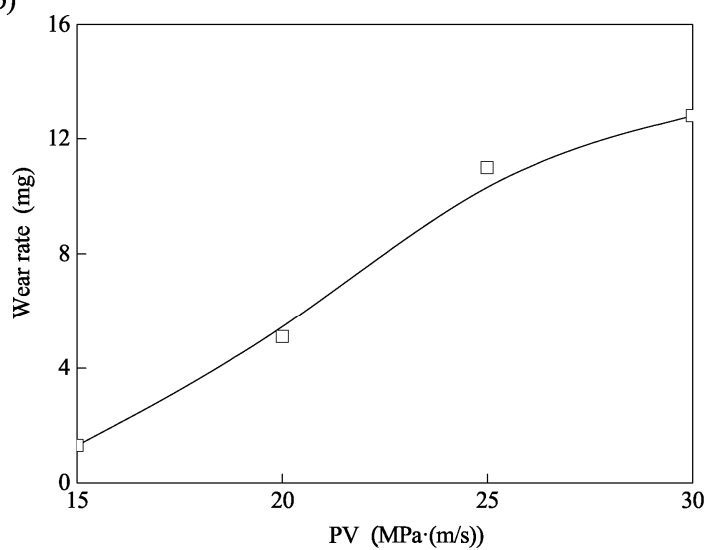

Fig. 12 (a) COFs and (b) wear rate with the S07 steel disk with DLC film under the water-lubricated conditions. (a)

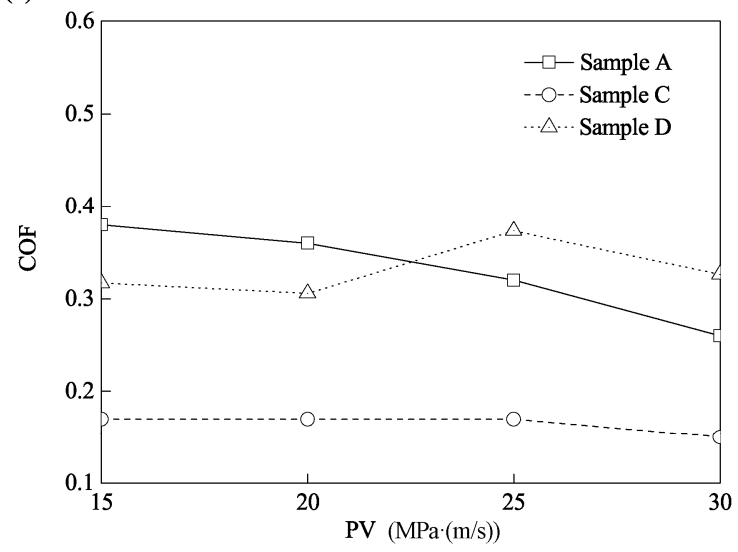

(b)

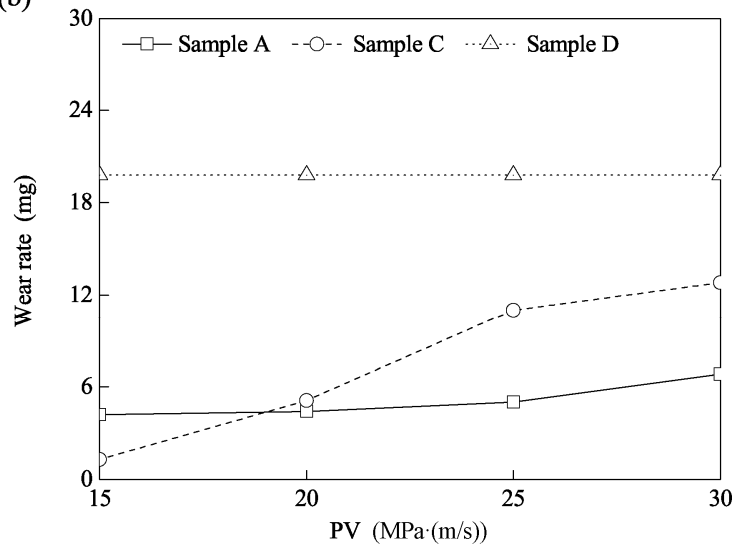

Fig. 13 (a) Average COF and (b) wear rate results with the different materials under the water-lubricated conditions.

Figure 14 shows that under the water-lubricated condition, the adhesion of the copper-based graphite occurs at the worn surface of the $\mathrm{S07}$ disk. The adhesion profile is granular, and the adhesion becomes more obvious with the increase in the load. Moreover, a slight scratch appears at the disk surface, and the scratches become more obvious with the increase in the load. Hence, the possible wear and failure mechanisms of the seal pair consisting of S07 steel (rotor) and copper-based graphite (stator) are adhesive wear and slight surface abrasion.

Figure 15 shows that the transfer film of the copper-based graphite adheres to the surface of the copper-chromium alloy disk, and a severe adhesion wear occurs. A furrow phenomenon appears, and the furrow effect increases with increasing PV values. Hence, the possible wear and failure mechanisms of the seal pair of copper-chromium alloy (rotor) and copper-based graphite (stator) are furrow wear and surface scratch, and a severe furrow effect may 

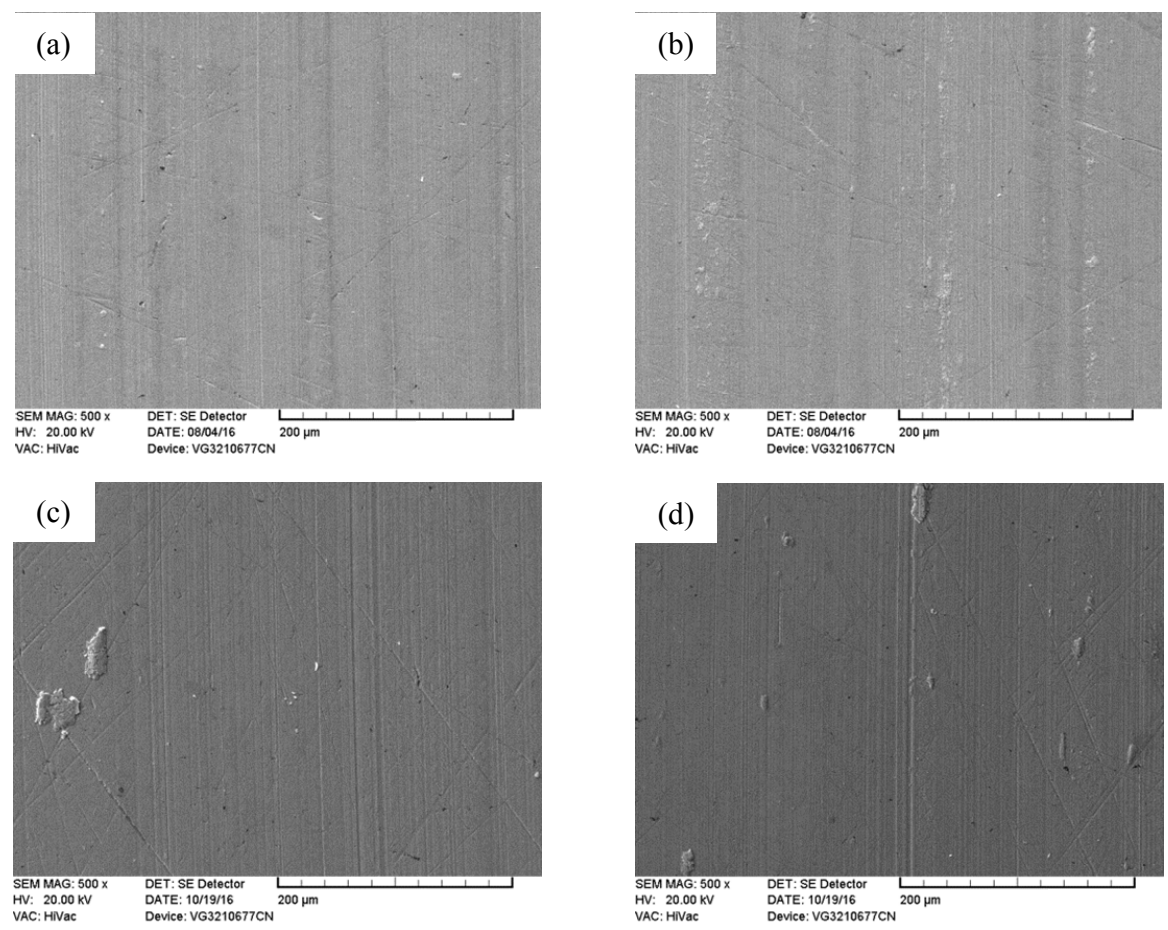

Fig. 14 Wear surface topography with the S07steel disk: PV = (a) $15 \mathrm{MPa} \cdot(\mathrm{m} / \mathrm{s})$, (b) $20 \mathrm{MPa} \cdot(\mathrm{m} / \mathrm{s}),(\mathrm{c}) 25 \mathrm{MPa} \cdot(\mathrm{m} / \mathrm{s})$, and (d) $30 \mathrm{MPa} \cdot(\mathrm{m} / \mathrm{s})$.
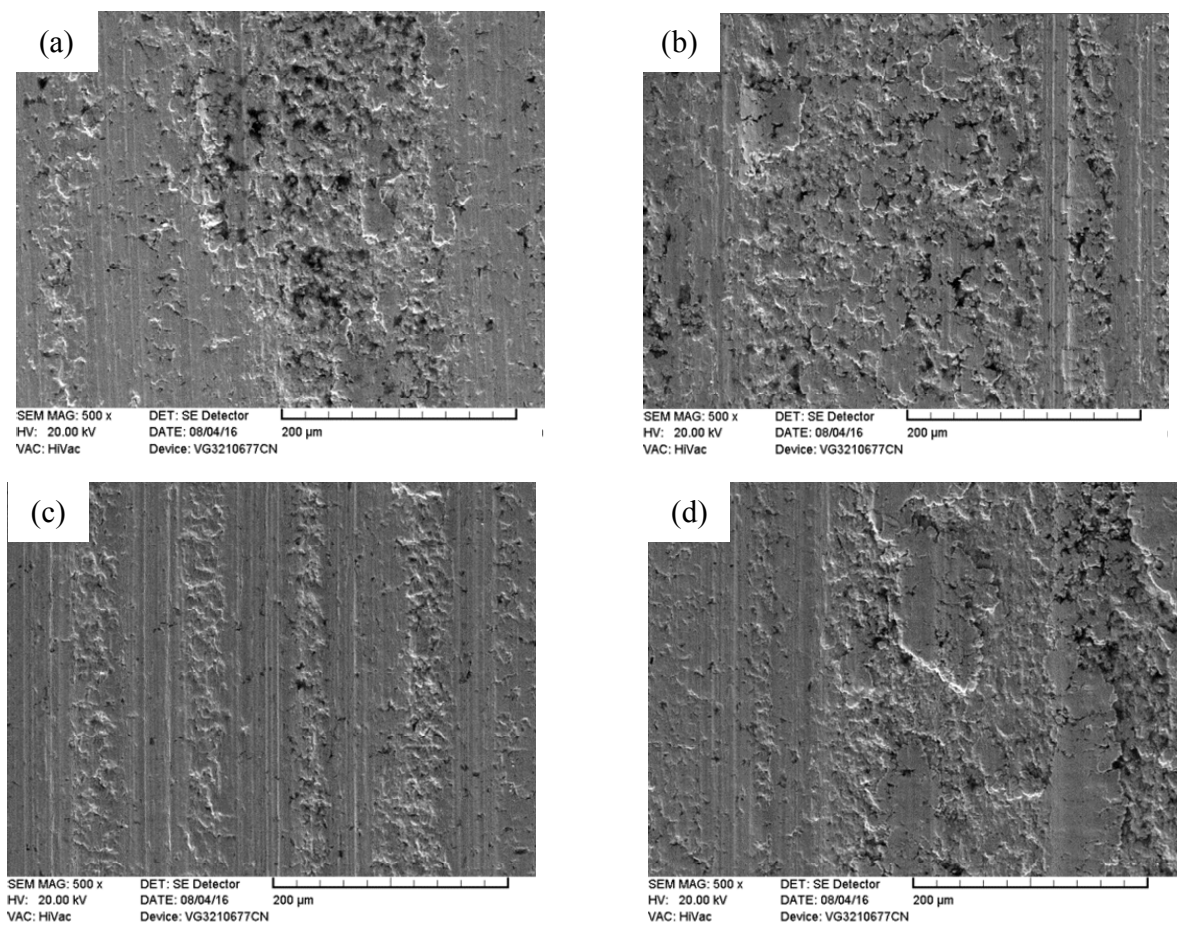

Fig. 15 Wear surface topography with the copper-chromium alloy disk: PV = (a) $15 \mathrm{MPa} \cdot(\mathrm{m} / \mathrm{s})$, (b) $20 \mathrm{MPa} \cdot(\mathrm{m} / \mathrm{s}),(\mathrm{c}) 25$ $\mathrm{MPa} \cdot(\mathrm{m} / \mathrm{s})$, and (d) $30 \mathrm{MPa} \cdot(\mathrm{m} / \mathrm{s})$,

lead to adhesion wear.

Figure 16 shows that the wear surface of the S07 steel disk with a DLC film almost does not change with the change in the PV values. Moreover, no obvious adhesion and scratches are observed. The results show that the S07 steel disk with a DLC 

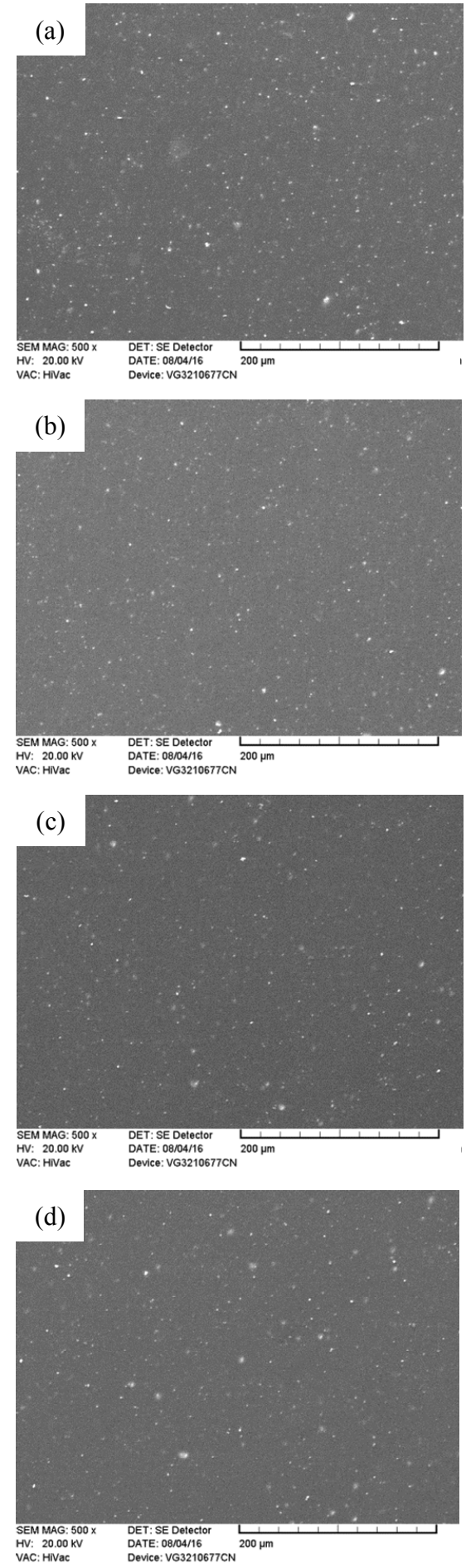

Fig. 16 Wear surface topography with the S07 steel disk with DLC film: PV = (a) $15 \mathrm{MPa} \cdot(\mathrm{m} / \mathrm{s})$, (b) $20 \mathrm{MPa} \cdot(\mathrm{m} / \mathrm{s})$, (c) $25 \mathrm{MPa} \cdot(\mathrm{m} / \mathrm{s})$, and (d) $30 \mathrm{MPa} \cdot(\mathrm{m} / \mathrm{s})$.

film exhibits good friction and wear behavior under the water-lubricated condition. The possible wear and failure mechanism of the seal pairs consisting of the DLC film (rotor) and copper-based graphite (stator) is material deformation from changes in severe working conditions (such as high-low temperature difference and high transient shock load).

\section{Conclusions}

1) Under a dry-friction condition, the average COFs of all disks decrease with the load except for the S07 steel disk and S07 steel disk with a DLC film. The other disks demonstrate a good anti-friction effect. Under different PV conditions, the wear rate increases with the increase in the load. The differences in the wear rate are very small. The wear rates of the copper-chromium alloy are the lowest.

2) Under the water-lubricated and high-PV value conditions, the COF and wear rate of the different pairs have a significant difference. The pair of the maximum difference between the coefficients is made of S07 steel disk. When the pair consists of the copper-based graphite pin and copper-chrome alloy disk, the pin wear is very serious. The DLC film exhibits good anti-friction performance, which may be more suitable for use as seals under waterlubricated conditions.

3) The surface morphology of the different materials under the water-lubricated condition shows that the wear surface of the S07 steel disk with a DLC film exhibits almost no change with the change in the PV values. Moreover, no obvious adhesion and scratches are observed. In summary, the pair of copper-based graphite (stator) and S07 steel with a DLC film (rotor) is a reasonable combination of seal materials under both dry-friction and waterlubricated conditions.

\section{Acknowledgements}

This study was supported by the National Natural Science Foundation of China (No. 51575418) and the Natural Science Foundation of Shaanxi Province of China (No. 2019JM-034).

Open Access This article is licensed under a Creative Commons Attribution 4.0 International License, which permits use, sharing, adaptation, distribution and reproduction in any medium or format, as 
long as you give appropriate credit to the original author(s) and the source, provide a link to the Creative Commons licence, and indicate if changes were made.

The images or other third party material in this article are included in the article's Creative Commons licence, unless indicated otherwise in a credit line to the material. If material is not included in the article's Creative Commons licence and your intended use is not permitted by statutory regulation or exceeds the permitted use, you will need to obtain permission directly from the copyright holder.

To view a copy of this licence, visit http://creativecommons.org/licenses/by/4.0/.

\section{References}

[1] Zhang G Y, Zhao W G. Design and experimental study on the controllable high-speed spiral groove face seals. Tribol Lett 53(2): 497-509 (2014)

[2] Zhang G Y, Chen G Z, Zhao W G, Yan X T, Zhang Y. An experimental test on a cryogenic high-speed hydrodynamic non-contact mechanical seal. Tribol Lett 65(3): 80 (2017)

[3] Yi M Z, He J W, Huang B Y, Zhou H J. Friction and wear behaviour and abradability of abradable seal coating. Wear 231(1): 47-53 (1999)

[4] Déprez P, Hivart P, Coutouly J F, Debarre E. Friction and wear studies using taguchi method: Application to the characterization of carbon-silicon carbide tribological couples of automotive water pump seals. Adv Mater Sci Eng 2009: 830476 (2009)

[5] Hirani H, Goilkar S S. Formation of transfer layer and its effect on friction and wear of carbon-graphite face seal under dry, water and steam environments. Wear 266(11-12): 1141-1154 (2009)

[6] Wang J L, Jia Q, Yuan X Y, Wang S P. Experimental study on friction and wear behaviour of amorphous carbon coatings for mechanical seals in cryogenic environment. Appl Surf Sci 258(24): 9531-9535 (2012)

[7] Young L, Benedict J, Davis J. Investigation of a unique macro/micro laser machined feature for mechanical face seals with low leakage, low friction, and low wear. In Proceedings of the ASME/STLE 2011 International Joint Tribology Conference, Los Angeles, California, USA, 2011: 211-214.

[8] Zhao X Y, Liu Y, Wen Q F, Wang Y M. Frictional performance of silicon carbide under different lubrication conditions. Friction 2(1): 58-63 (2014)

[9] Frölich D, Magyar B, Sauer B. A comprehensive model of wear, friction and contact temperature in radial shaft seals. Wear 311(1-2): 71-80 (2014)

[10] Cui G J, Li J X, Wu G X. Friction and wear behavior of bronze matrix composites for seal in antiwear hydraulic oil. Tribol Trans 58(1): 51-58 (2015)

[11] Towsyfyan H, Gu F, Ball A D, Liang B. Tribological behaviour diagnostic and fault detection of mechanical seals based on acoustic emission measurements. Friction 7(6): 572-586 (2019).

[12] Zhang G Y, Yan X T, Zhang Y, Zhao W G, Chen G Z. Study on the water-lubricated high-speed non-contact mechanical face seal supported by a disc spring. J Braz Soc Mech Sci Eng 40(7): 351 (2018)

[13] Vila M, Carrapichano J M, Gomes J R, Camargo Jr S S, Achete C A, Silva R F. Ultra-high performance of DLC-coated $\mathrm{Si}_{3} \mathrm{~N}_{4}$ rings for mechanical seals. Wear 265(5-6): 940-944 (2008)

[14] Shankar S, Kumar P K. Frictional characteristics of diamond like carbon and tungsten carbide/carbon coated high carbon high chromium steel against carbon in dry sliding conformal contact for mechanical seals. Mech Ind 18(1): 115 (2017)

[15] Erdemir A, Martin J M. Superior wear resistance of diamond and DLC coatings. Curr Opin Solid State Mater Sci 22(6): 243-254 (2018)

[16] Zhang G Y, Dang J Q, Zhao W G, Yan X T. Tribological behaviors of the thick metal coating for the contact mechanical seal under the water-lubricated conditions. Ind Lubr Tribol 71(2): 173-180 (2019)

[17] Gao S Y, Xue W H, Duan D L, Li S. Tribological behaviors of turbofan seal couples from friction heat perspective under high-speed rubbing condition. Friction 4(2): 176-190 (2016)

[18] Zhang G Y, Yuan X Y, Dong G N. The tribological behavior of $\mathrm{Ni}-\mathrm{Cu}-\mathrm{Ag}$-based PVD coatings for hybrid bearings under different lubrication conditions. Tribol Int 43(1-2): 197-201 (2010)

[19] Zhang G Y, Zhao W G, Yan X T, Yuan X Y. A theoretical and experimental study on characteristics of waterlubricated double spiral-grooved seals. Tribol Trans 54(3): 362-369 (2011)

[20] Zhang G Y, Zhao W G, Tian Y X. Experimental study on the water lubrication of non-contacting face seals for turbopumps. Ind Lubr Tribol 66(2): 314-321 (2014) 


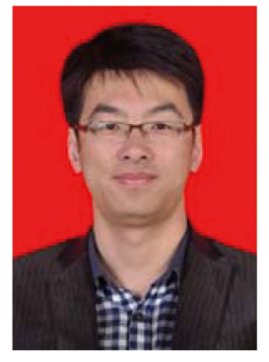

Weigang ZHAO. He received the M.S. degree in mechanical engineering in 2005 from Northwestern Polytechnical University (NPU), China. He started to work at Xi'an

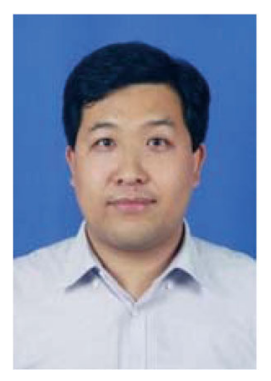

Guoyuan ZHANG. He received the M.S. degree in mechanical engineering in 2004 from NPU, China. He received the Ph.D. degree in mechanical engineering in 2009 from Xi'an Jiaotong University, China. He worked at NPU as a

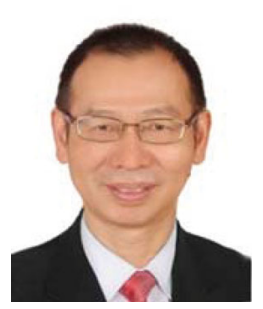

Guangneng DONG. He received his M.Phil. and Ph.D. degree from Theory of Lubrication and Bearing Institute in Xi'an Jiaotong University (China) in 1989 and 1999, respectively. Dr. DONG currently is a professor at the School of
Aerospace Propulsion Institute of China Aerospace Science and Technology Corporation in 2003 and has been working on Turbopump system design and experiments. He is currently a Ph.D. candidate in the School of Astronautics, NPU.

postdoctoral fellow from 2010 to 2013. He has joined the School of Electromechanical Engineering of Xidian University from 2013 and has been working on theoretical and experimental research and development on tribology (bearing, seal, lubricate, etc.), mechatronic system dynamics, and mechanical design method.

Mechanical Engineering of Xi'an Jiaotong University. His research interests are lubrication design and optimization of major equipment, advanced manufacturing and ultra-smooth surface technology, micro-nano surface/interface design, and surface engineering. 